\title{
PRESENTATION OF PREVIOUSLY ASYMPTOMATIC AND UNDIAGNOSED CHIARI I MALFORMATION FOLLOWING SPINAL ANAESTHESIA - DIFFERENTIAL DIAGNOSIS OF HEADACHE -
}

Luis Lopes 1, Mihran Portugalyan 1

1- Serviço de Anestesiologia, Reanimação e Dor, Hospital Professor Doutor Fernando Fonseca

\section{BACKGROUND AND AIMS}

Type I Chiari malformation manifests with caudal displacement of the cerebellar tonsils below the level of the foramen magnum. Often diagnosed in adulthood, patients may present with headache and neck pain. We describe a case of a patient who was retrospectively diagnosed with Chiari malformation type I following spinal anaesthesia, while having other potential causes of headache.

\section{METHODS \\ G27 bisel needle \\ Median approach, L3-L4}

Identification: Female, 24 years old, ASA I.

Procedure: Pilonidal sinus excision (uneventful).

Technique: Saddle block anaesthesia. Landmark-based technique with administration of $0,5 \%$ bupivacain.

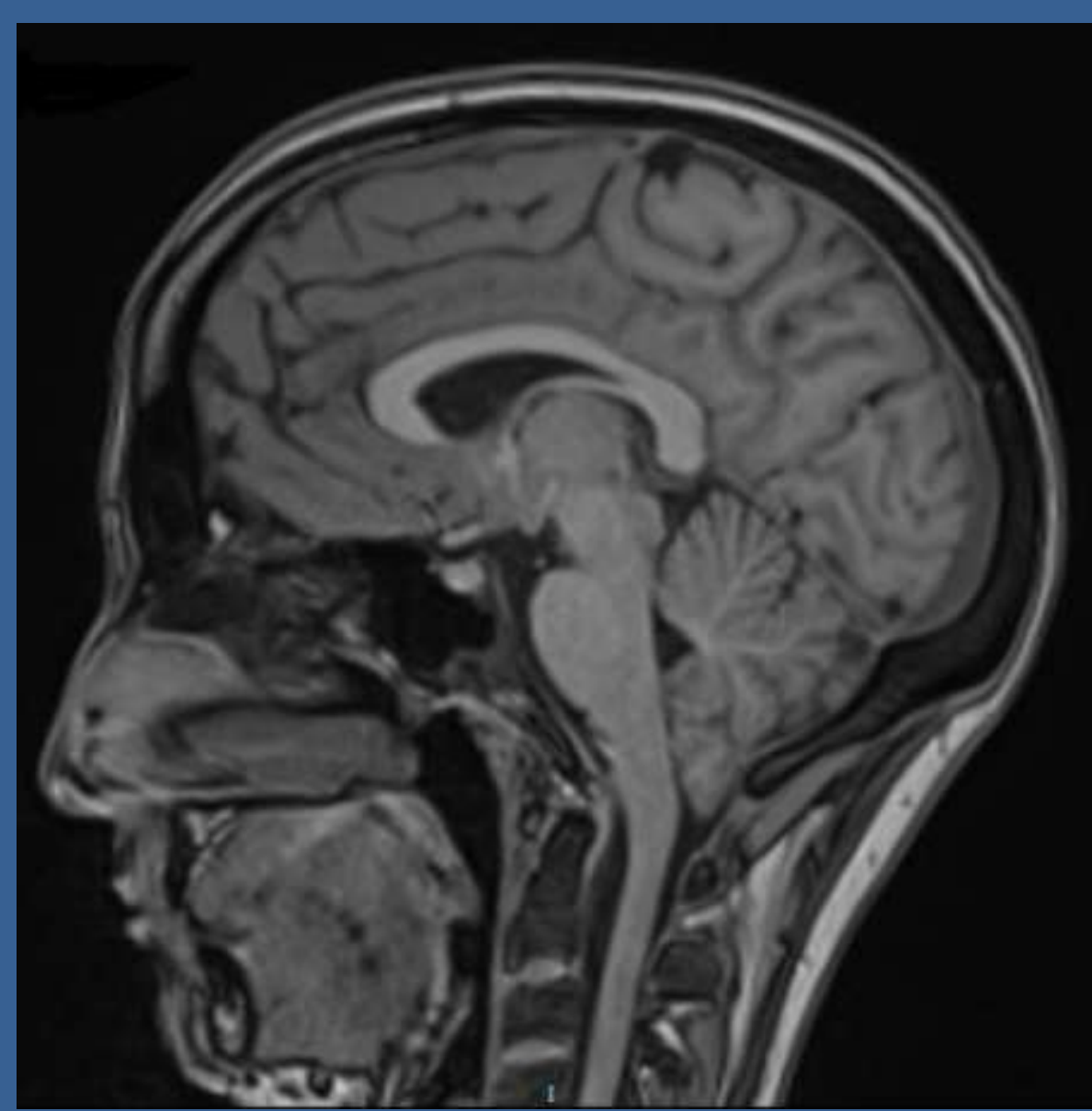

Chiari malformation type I (Fig.1): Patient's head MRI (sagittal cut) revealing a downard displacement of the cerebellar tonsils through the foramen magnum.

\section{RESULTS}

One hour after the procedure she developed bilateral parietal headaches accompanied by kinesiophobia, nausea and vomiting, unrelated with positioning. Forty-eight hours later the patient developed a pronounced aggravation of the headache with orthostatic position, wich relieved with decubitus. She was medicated with analgesics and oral caffeine and discharged from the hospital after a few days with complete resolution of symptoms. The head MRI revealed a $7.5 \mathrm{~mm}$ descent of the caudal tip of the cerebellar tonsils past the foramen

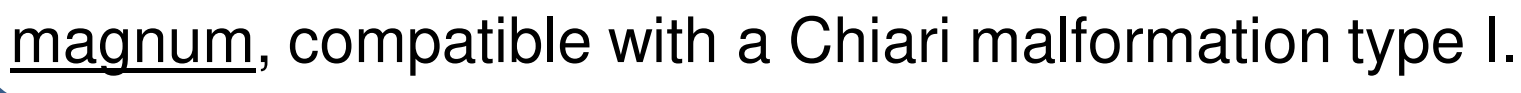

\section{CONCLUSIONS}

The CSF leakage into the epidural space after a dural puncture may lead to further descending of the tonsils on a patient with Chiari malformation type I, thus leading to headache. The diagnosis may be challenging especially when in the presence of other possible causes for this symptom, such as postdural punction headache. This case emphasizes the importance of a careful differential diagnosis of headaches that arise after a spinal anaesthesia. 